\title{
Effect of upper extremity exercise and respiratory training on the quality of life in patients with Chronic Obstructive Pulmonary Disease in Velayat Hospital, Qazvin, Iran
}

\author{
L. Yekefallah ${ }^{1}, \underline{\text { O. Keshavarz Sarkar }}{ }^{1}$, MA. Zohal$^{2}$, A. Barikani ${ }^{3}$
}

\footnotetext{
${ }^{1}$ Department of Intensive Care, Qazvin University of Medical Sciences, Qazvin, Iran

${ }^{2}$ Qazvin University of Medical Sciences, Qazvin, Iran

${ }^{3}$ Department of Social Medicine, Qazvin University of Medical Sciences, Qazvin, Iran
}

Corresponding Address: Omolbanin keshavarz Sarkar, Qazvin University of Medical Sciences, Faculty of Nursing and Midwifery Tel: +98-28-33338034; Email: sarkar.keshavarz@ gmail.com

Received: 10 April 2018; Accepted: 8 July 2018

\section{Abstract}

Background: Chronic obstructive pulmonary disease (COPD) is a major public health challenge and also the leading cause of death in the world. Evidences indicate that this disease ranking will be rising from $4^{\text {th }}$ to $3^{\text {rd }}$ until 2020.

Objective: The purpose of this study was to compare the effect of upper extremity exercise and respiratory training on the quality of life in patients with COPD.

Methods: This randomized clinical trial study conducted in Velayat Hospital in Qazvin with COPD patients $(n=75)$ in 2017. After dividing the participants into three groups $(n=25)$, demographic information and St George's quality of life questionnaire were completed. The upper extremity exercise group attended in 12 exercise sessions and the respiratory training group received respiratory trainings for one month, as well. Data were analyzed by independent t-test, one-wayANOVA test, and Paired t-test.

Findings: The upper extremity exercise group had a higher quality of life than the respiratory training group $(\mathrm{P}=0.001)$.

Conclusion: Upper extremity exercises have been effective in increasing the quality of life of these patients. Therefore it can be used as a supplementary non-drug therapy.

Keywords: Exercise, Upper extremity, Breathing exercise, Chronic obstructive pulmonary disease (COPD), Quality of life

Citation: Yekefallah L, Keshavarz Sarkar O, Zohal MA, Barikani A. Effect of upper extremity exercise and respiratory training on the quality of life in patients with Chronic Obstructive Pulmonary Disease in Velayat Hospital, Qazvin, Iran. J Qazvin Univ Med Sci 2018; 22(5): 51-58. 


\section{مقايسه تأثير ورزش اندامهاى فوقانى و تمرينهاى تنفسى بر كيفيت زندَّى مبتلايان به بيمارى

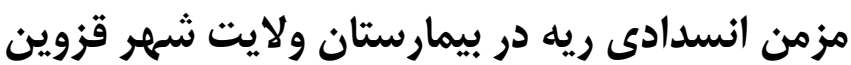

دكتر ليلى يكه فلاح'، ام البنين كشاورز سركار '، دكتر محمدعلى زحل'، دكتر آمنه باريكانى'

| كروه مراقبتهاى ويثره دانشكاه علوم يزشكى قزوين، قزوين، ايران

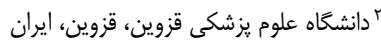

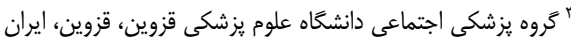

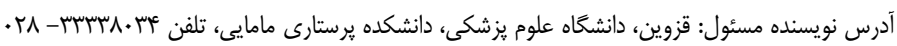

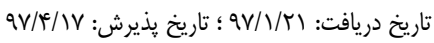

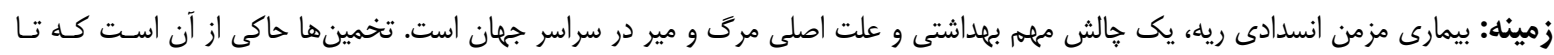

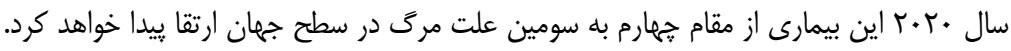

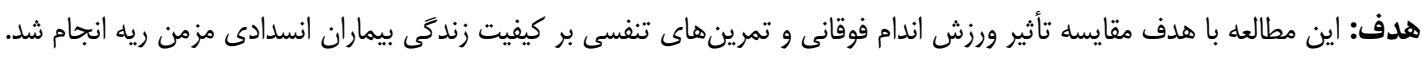

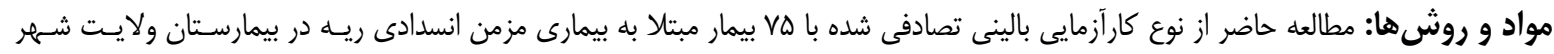

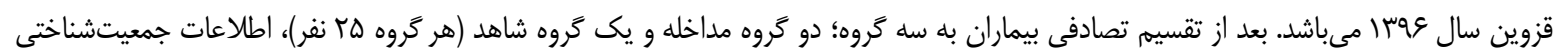

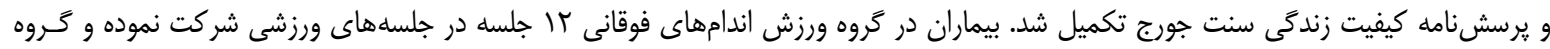

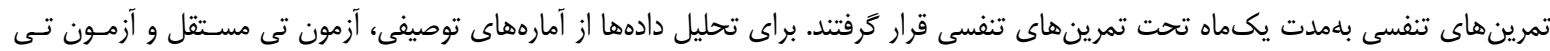
زوجى استفاده كَرديد.

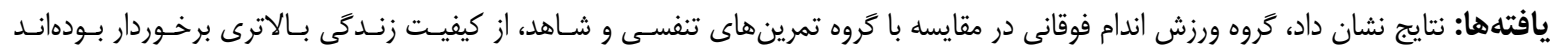
. $(\mathrm{P}=\cdot / \cdot .1)$ نتيجهَّيرى: شركت در تمرينهاى ورزشى اندامهاى فوقانى در افزايش ميزان كيفيت زندَّى اين بيماران مـؤثر بـوده، لـذا از ورزش انـام فوقانى مى توان بلعنوان درمان تكميلى غيردارويى استفاده نمود.

كليدوازهها: ورزش، اندام فوقانى، تمرينهاى تنفسى، بيمارى مزمن انسدادى ريه، كيفيت زندگى

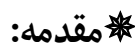

يانصد هزار مراجعل كننده به بخش اورزانس در ارتبـاط بـا اين بيمارى وجود دارد و هر ساله در حدود . V هزار بيمار

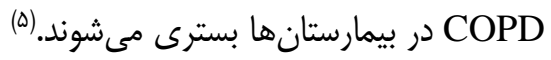

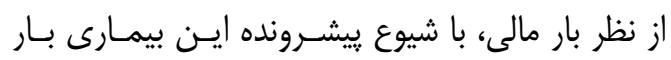

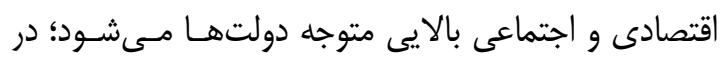
كشورهاى اتحاديه ارويا هزينه مستقيم درمان اين بيمارى

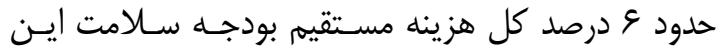

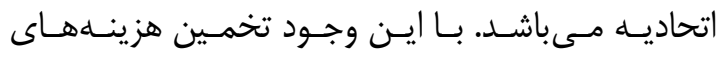

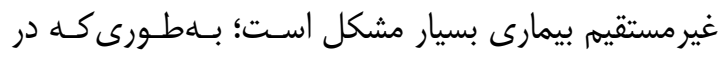

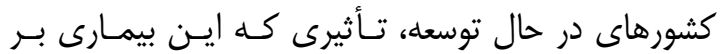

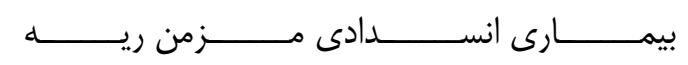

(COPD; Chronic obstructive pulmonary disease)

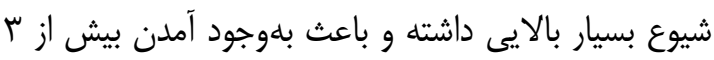

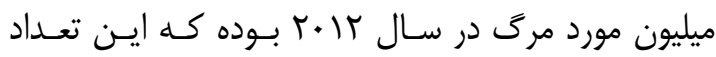

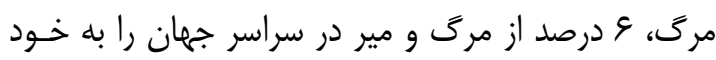

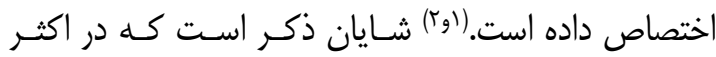

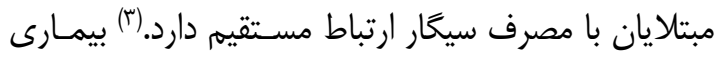

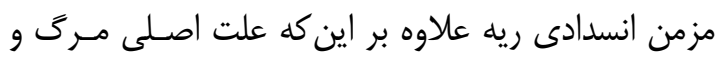
مير در جهان است، بار اقتصادى و اجتماعى بالايى نيز بـانـا

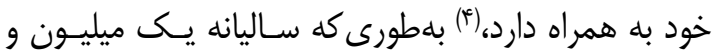




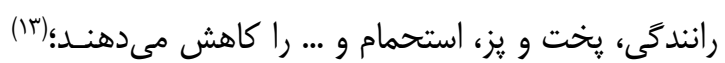

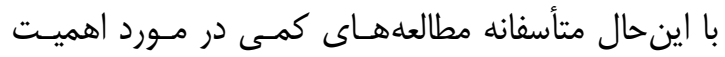

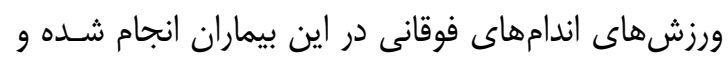

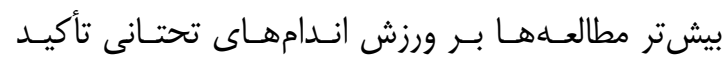

داشتهاند. (If)

شناسايى بيماران با قدرت كاهش يافته در اندام فوقانى

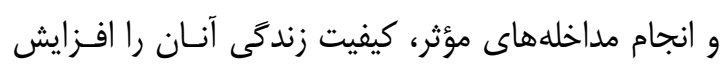

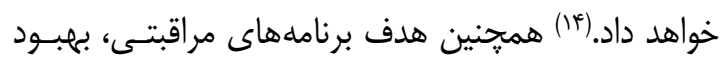

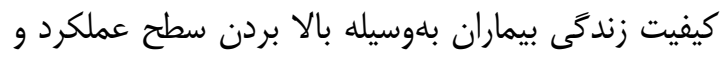

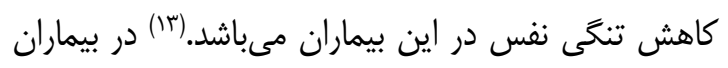

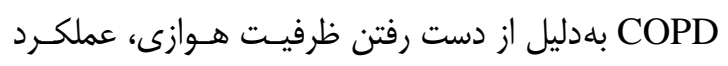

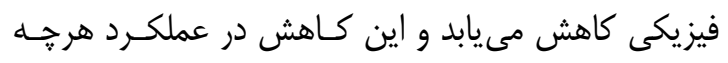

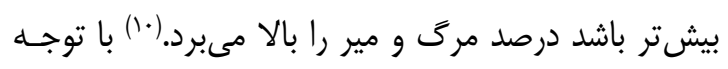

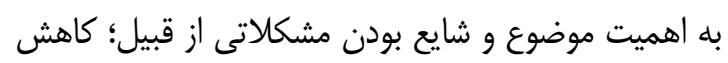
كيفيت زندگى و مشكلات زيادى كه اين بيماران در انجام

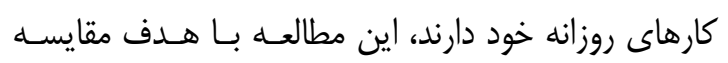

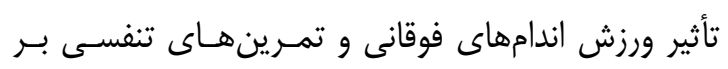

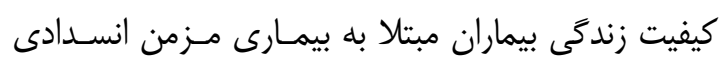

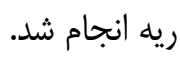

\section{مواد و روشها:}

يثوهش حاضر يـك مطالعـه كارآزمـايى بـالينى سـهـ

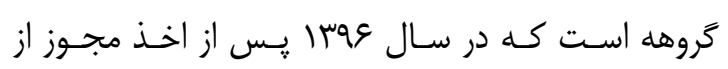

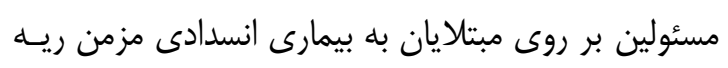

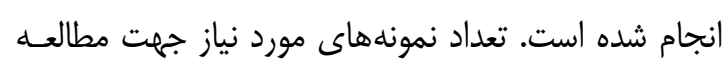

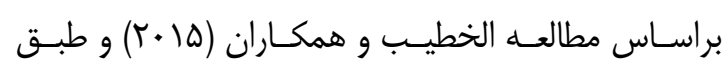

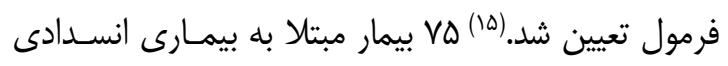

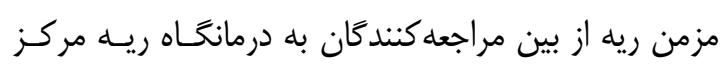

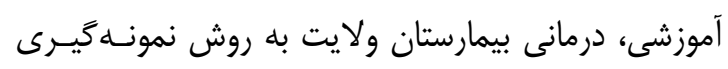

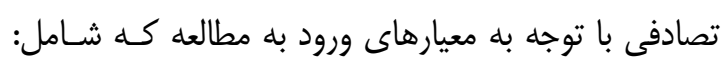

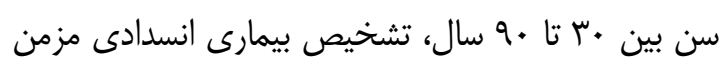

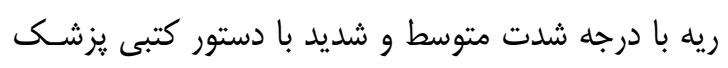

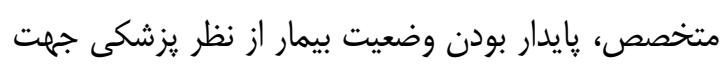

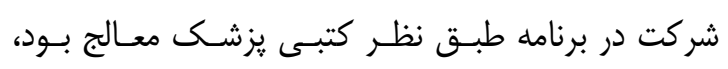

عملكرد فرد در امـور خانسه و كـارايى وى در محـيط كار

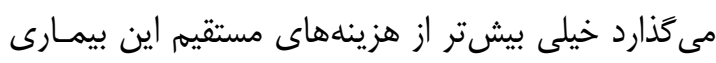

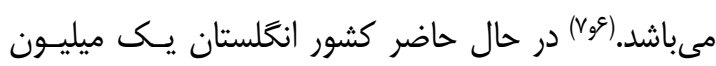

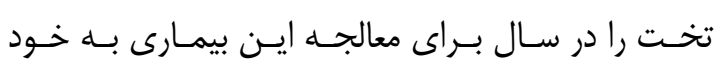

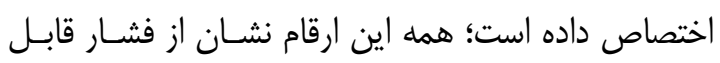

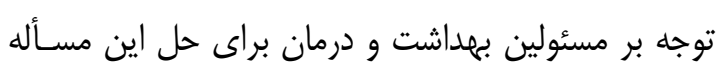
(ᄉ). دارد. امروزه افـزايش هزينـهـهـاى بسـترى در بيمارسـتان،

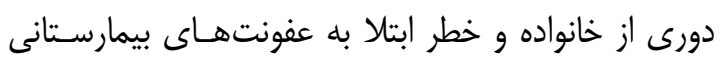

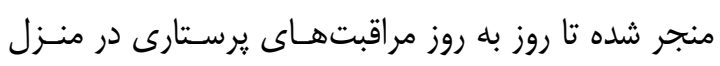

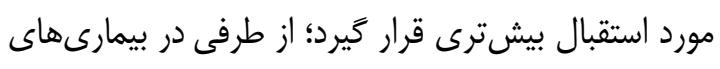

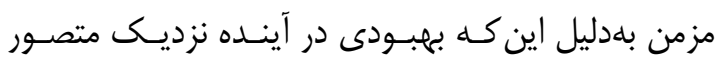

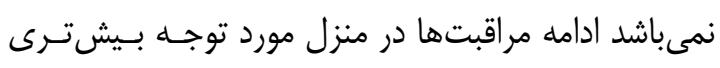

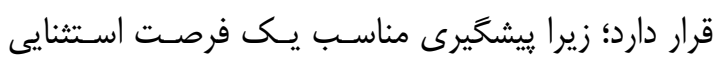

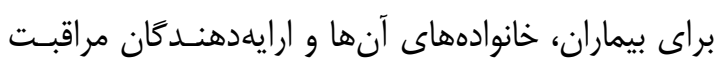

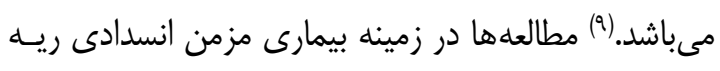

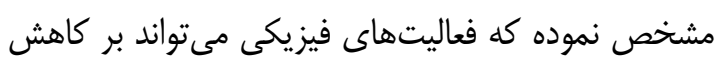

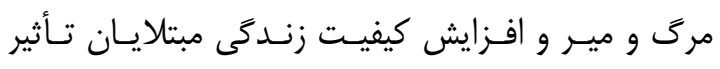

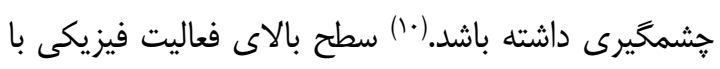

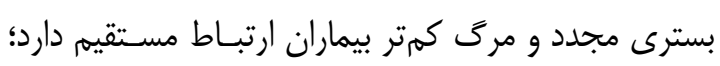

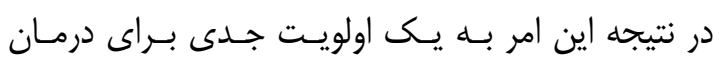

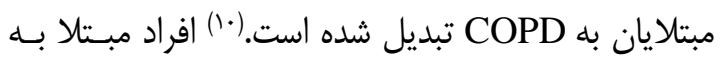

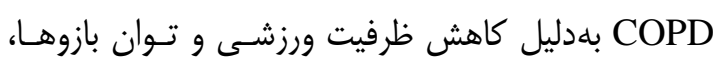

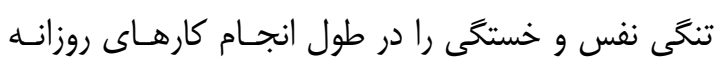

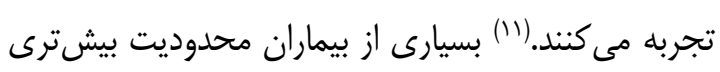

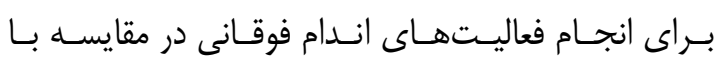

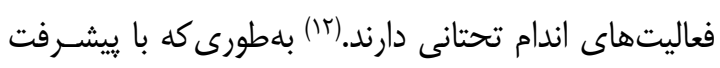

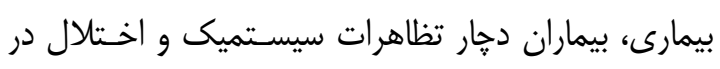

عملكرد عضلههاى محيطى مى شوند.."

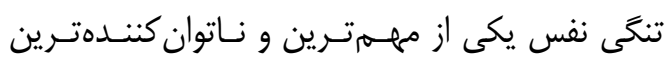

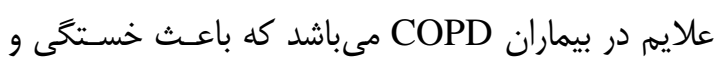

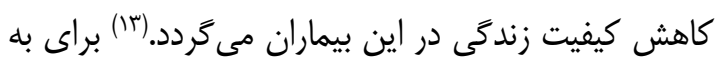

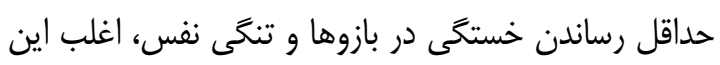

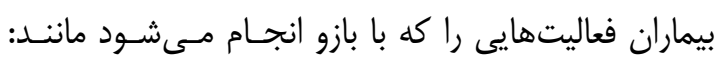


اكسى مترى جهت ارزيابى بيماران و آمـادگى آنـان بـراى

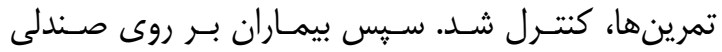

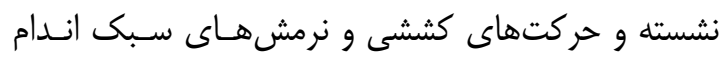

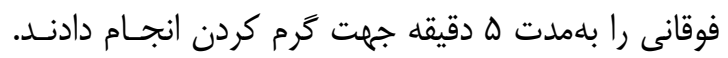
اين حركتهاى ورزشى با وزنههاى يكى تـا دو كيلـوكرمى إنى

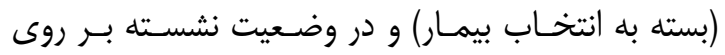

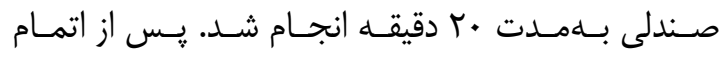

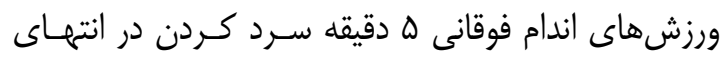

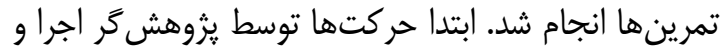

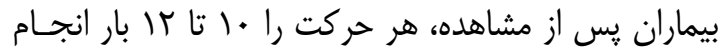

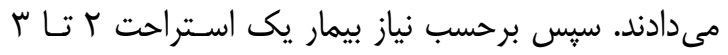

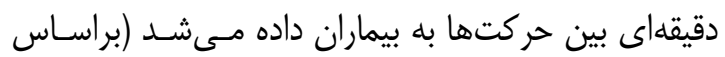

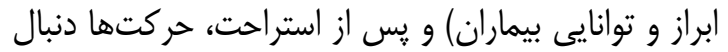

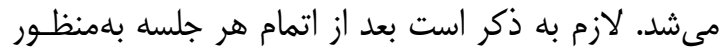

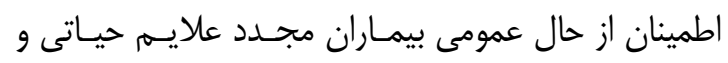

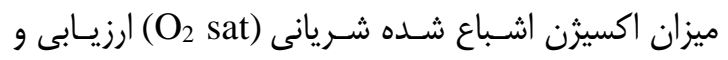

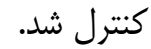
ه ب بيمار ديخر، در خـروه شـاهد تحـت مراقبـتهـاى

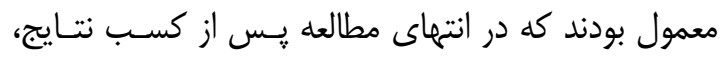
براى جلوگيرى از مشكل اخلاقى نتيجه تحقيق در اختيـار آنان قرار كرفت. در اين يثوهش ابزار جمع آورى اطلاعات يرسشنامه اطلاعات جمعيتى شامل؛ جنس، سن، وضعيت تأهل، سطح تحصيلات، شغل، مدت زمان ابتلا به بيمارى

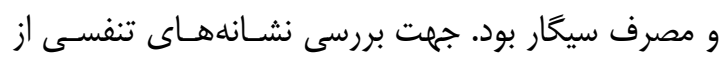

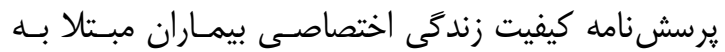

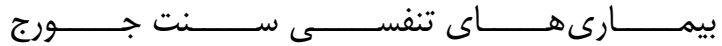

(St georg respiratory questionnair; SGRQ) استفاده شد.(1) اين بخش شـامل سـه حيطـ؛ نشـانههـا،

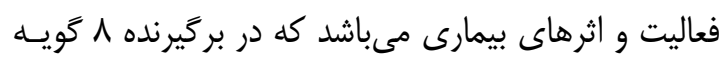
و سؤالاتى در رابطه با سرفه، توليد خلط، كوتـاهى تـنفس، خس خس ســينه و مشـكلات ريـوى مسباشــــ در ايـن

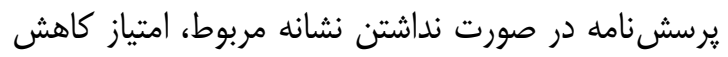

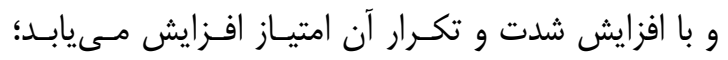
بلهورى كه امتياز صفر نشاندهنده نبود نشانههاى تنفسى

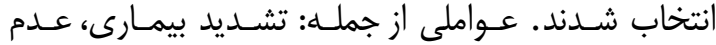

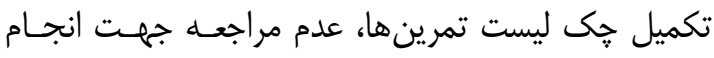

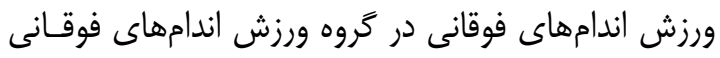

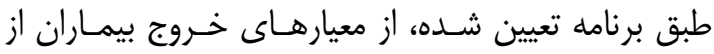
مطالعه در نظر كرفته شد. از بين VD بيمار واجد شرايط با تخصيص تصادفى بـهـ

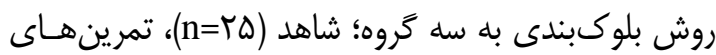

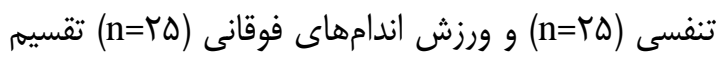

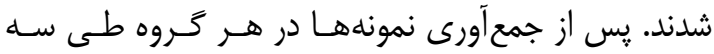

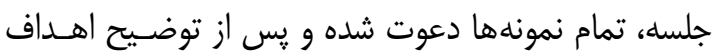
يثوهش براى هر بيمار در صورت داشتن رضايت و تكميل

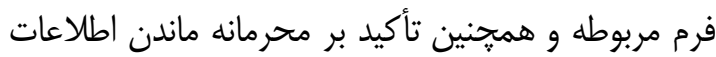

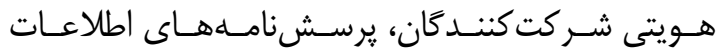

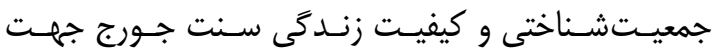
مقايسه پֶ از مداخلهها تكميل گر ديد. بيمار ان در گروه تمرينهاى تنفسى، تمرينهاى منظمه

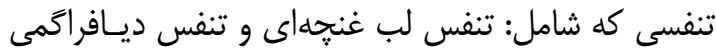
مىباشد را توسط يزوهش

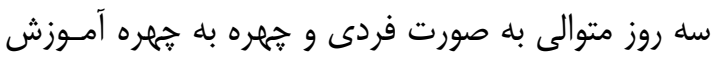
ديدند. يّ از اطمينان از فراكيرى مددجويان، خكى ليست تمرينهاى تنفسى به آنان داده شد تا هر روز يس از از انجام

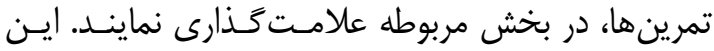

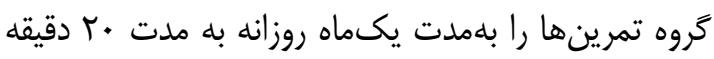
و جهار بار در روز (صبح ، ظهر، عصر و شب) انجام دادنـد. همجنين به بيماران الخوى مناسب يك دقيقه تمرين و دو دقيقه استراحت آموزش داده شد و ييخيرى انجام تمرينها روزانه توسط يزوهش هفته هر روز انجام يذيرفت.

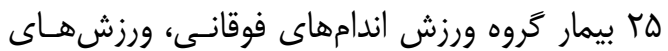

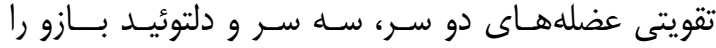

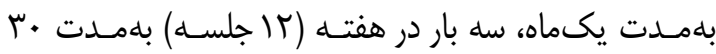

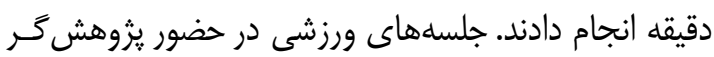
در مركز بازتوانى قلبى - ريوى بيمارسـتان ولايـت انجـام يذيرفت. در هر جلسه قبل از شروع، علايم حياتى و يالس 
درصد) از آنان شاغل بودند. همجنين يافتهها نشان داد كه

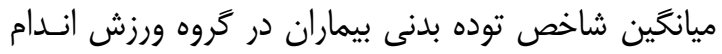
فوقانى / گروه شاهد ف/

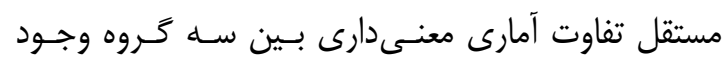
نداشت. علاوه بر اين قبل از مداخله، مقايسه بـين ميـانغين و انحراف معيار نمرههاى كيفيت زندگى و سه حيطه نشانهانها

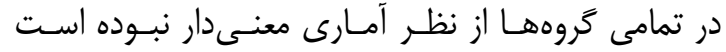

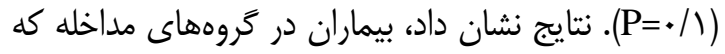
از تمرينهاى تنفسى و ورزش اندامهاى فوقانى بهره برده

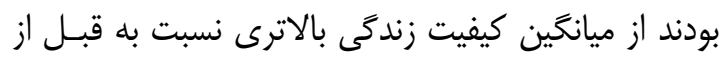
مداخله در تمامى حيطههاى كيفيت زندكى برخوردار شدند

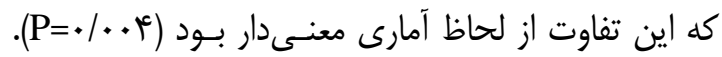

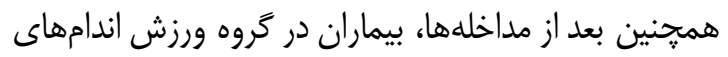

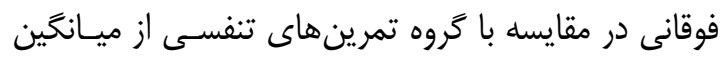

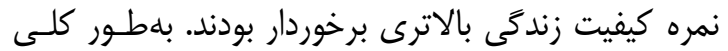

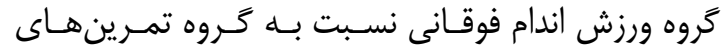

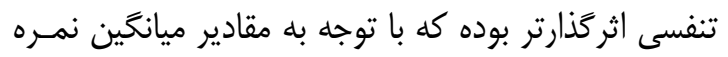

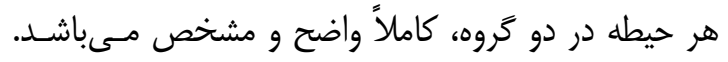

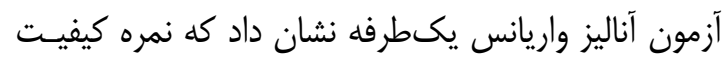

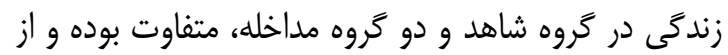

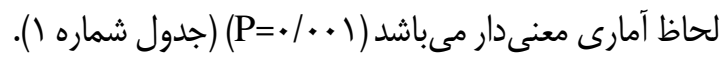

و امتياز ·. ( نشاندهنده بـيشتـرين شـدت نشـانههـاى

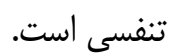
براى توصيف دادهها از آمارههـاى توصـيفى اسـتفاده

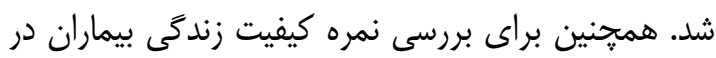

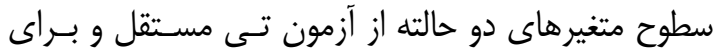

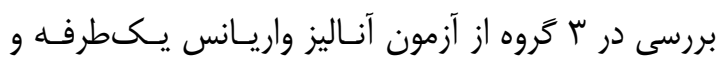

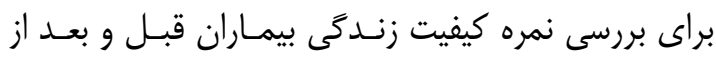

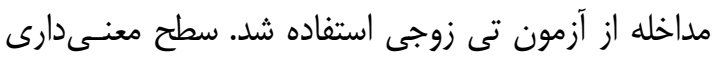
كهتر از هـ/• در نظر كرفته شد.

\section{(1) يافتهها:}

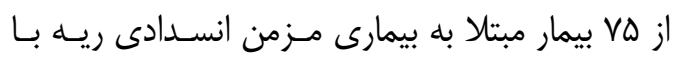

درجه شدت متوسط و شديد، كه با دستور كتبـى يزشـك متخصـص وارد مطالعـه شــندأ ميـانخين سـنى بيمـاران

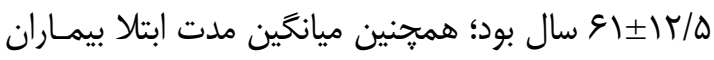
 مزمن انسدادى ريه مبتلا بودند.

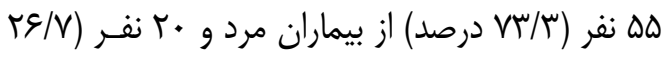

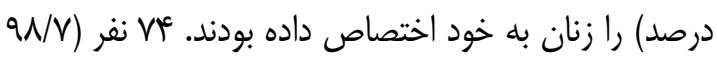

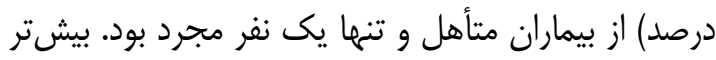

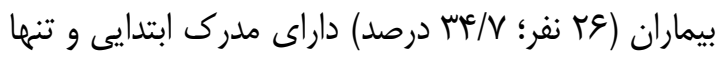

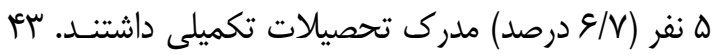

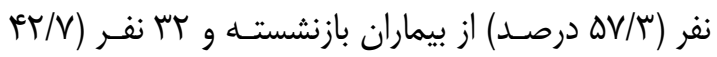

جدول ا- نتايج بررسى نمرههاى كيفيت زندگى در سه گروه قبل و بعد از مداخله

\begin{tabular}{|c|c|c|c|c|c|}
\hline نتيجه آزمون آناليز واريانس & تمرينهاى تنفسى & ورزش اندامهاى فوقانى & شاهد & & كروه \\
\hline • & $19 / \lambda \pm 4 / q$ & $\mid \mu / \varepsilon \pm \Delta / \mu$ & $\mid \varphi / r \pm \varepsilon / \Lambda$ & قبل & \multirow{2}{*}{ علايهم و نشانههاى بيمارى } \\
\hline$<\cdot 1 \cdot+1$ & $1 \cdot 1 \cdot \Lambda \pm \varepsilon / \wedge^{*}$ & $\Lambda / € \pm \Delta / \Lambda^{*}$ & $19 / 91 / 1$ & بعد & \\
\hline- & $N / T$ & $1 / \cdot 9$ & $-1 / \mu$ & & نتايج آزمون تى زوجى (paire-t-test) \\
\hline$\cdot / \pi$ & $9 / v \pm \leftarrow / 1$ & $N / I \pm Y / \Gamma^{c}$ & $9 \pm \Gamma / \Gamma$ & قبل & \multirow{2}{*}{ تأثير بر عملكرد اجتماعى } \\
\hline$<\cdot / \cdot+$ & $\Delta / V \pm \Psi / \Delta^{*}$ & $\Delta / \mathcal{\varepsilon} \pm \mu^{*}$ & $\mid r / \omega \pm r / \varepsilon$ & بعد & \\
\hline- & $\mathrm{V} / \cdot \mathrm{I}$ & $\Delta / \mu$ & $-r / 1$ & & نتايج آزمون تى زوجى \\
\hline.$/ 1$ & $r \cdot / r \pm \varepsilon / r$ & $\mid V / \wedge \pm \Delta / \&$ & $\mathrm{WN} \pm \mathrm{Y} / \mathrm{V}$ & قبل & \multirow{2}{*}{ فعاليتهاى روزانه } \\
\hline$<\cdot / \cdot+1$ & $W / \cdot r \pm \Delta / V^{*}$ & $\mid \omega / \kappa^{ \pm} \pm \Delta / r^{*}$ & $r \Delta / \Lambda \pm \varepsilon / \mu$ & بعد & \\
\hline- & $V / \Gamma$ & Q/4 & -1 & & نتايج آزمون تى زوجى \\
\hline.$/ 1$ & $\mid \varphi / \Lambda \pm 1 r / r$ & $r q / 8 \pm 11 / 9$ & $F T / I \pm I$. & قبل & \multirow{2}{*}{ كيفيت زندگى } \\
\hline$<\cdot / \cdot+1$ & $\mathrm{r} / \Lambda \pm I r / \Lambda^{*}$ & $r q / v \pm 11 / \Delta^{*}$ & $\Delta \xi / q \pm 1 \% / q$ & بعد & \\
\hline- & $1 \cdot / 19$ & $V / 9$ & $-\mu / \varepsilon$ & & نتايج آزمون تى زوجى \\
\hline
\end{tabular}


انسدادى مـزمن ريسه جهـت بررسـى رابطـهـه هارامترهـاى 

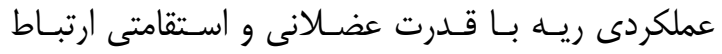
معنى دارى بين ميزان قدرت عضلههاى دست و متغيرهاى

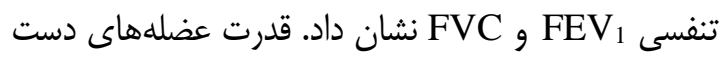
در افراد مبتلا به بيمارى مزمن انسدادى ريه در مقايسه با

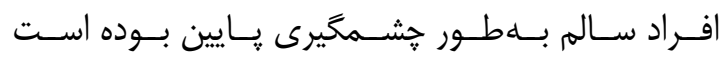
(11) $(\mathrm{P}<\cdot 1 \cdot \cdot 1)$

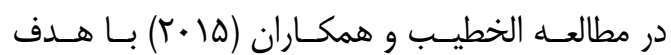

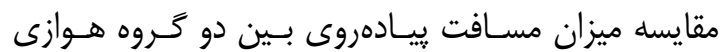

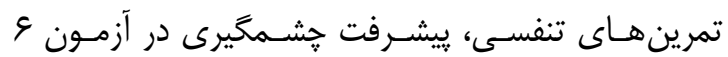

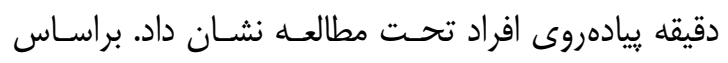

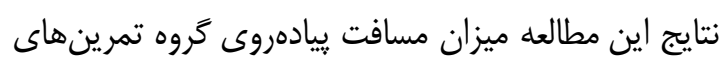

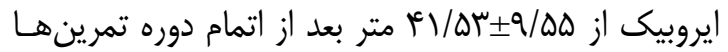

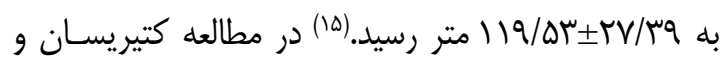

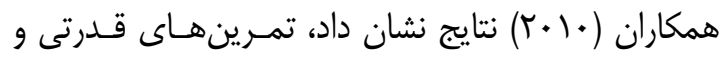

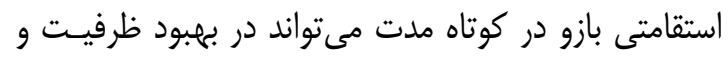

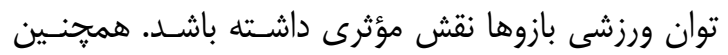
ورزشهايى كه بـدون حمايـت از بـازو انجـام مسىشـوند

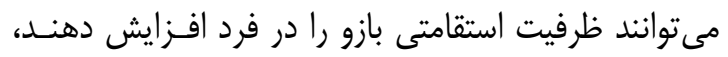

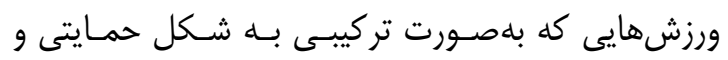

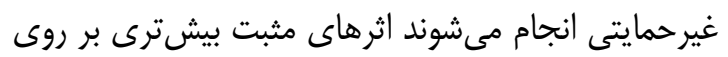
ظرفيت و توان ورزشى بازوها دارند.

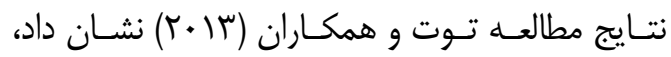

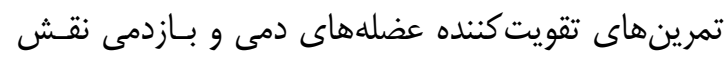

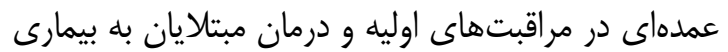

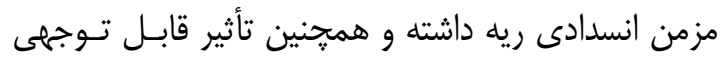

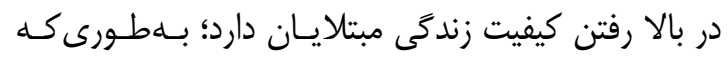

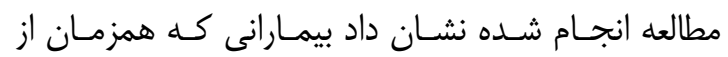

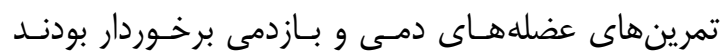

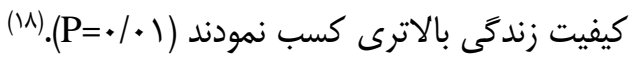

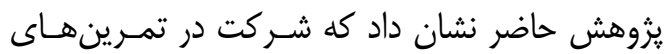

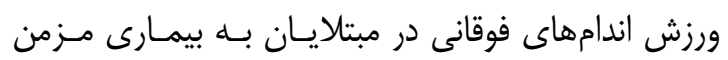
انسدادى ريه موجب افزايش ميزان كيفيت زندكى بيماران

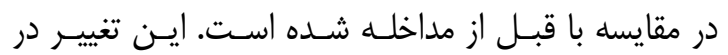

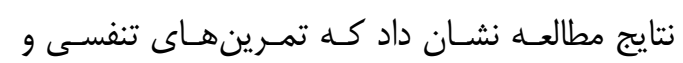

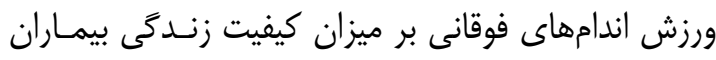

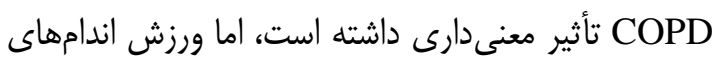

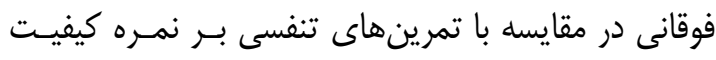

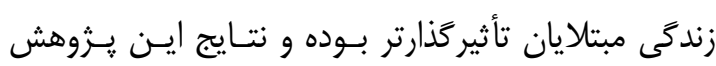

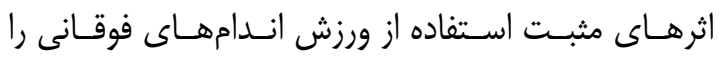

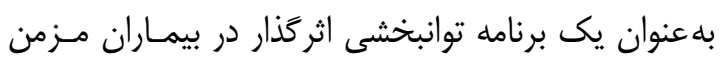

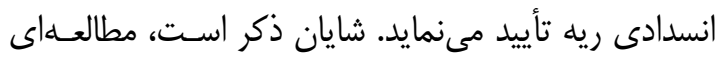

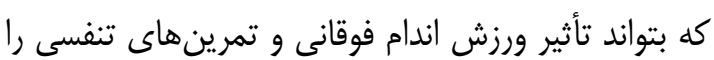

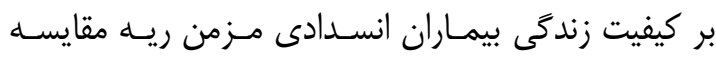

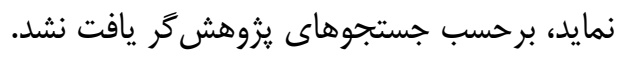

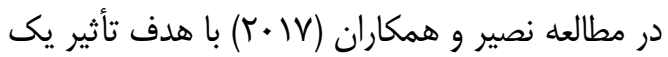

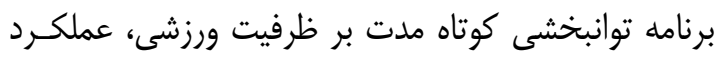

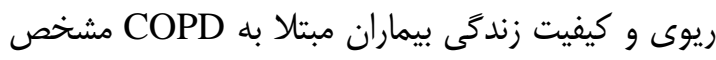

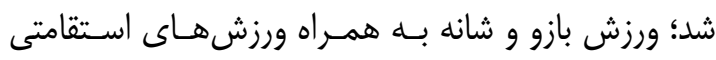

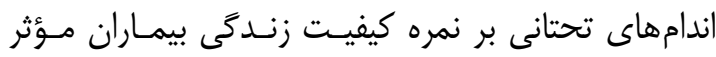

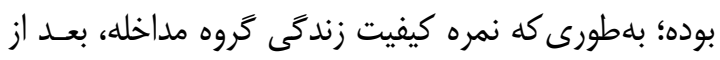

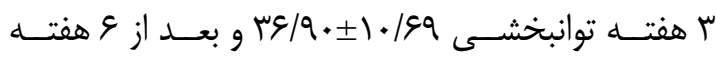

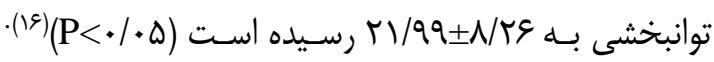

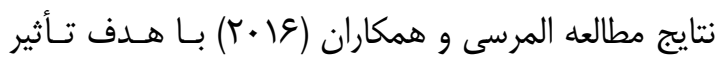
تمرينهاى عضلههاى دمى بر روى كيفيت زندكى بيمار ماران

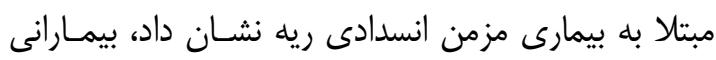

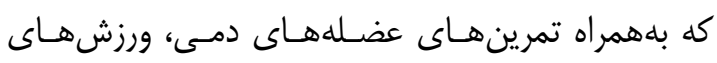
عضلانى محيطى را نيز دريافت كرده بودند در مقايسه بـا

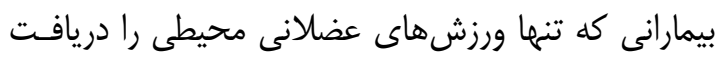

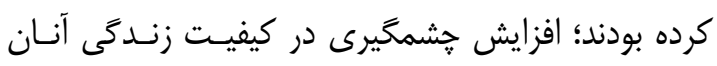

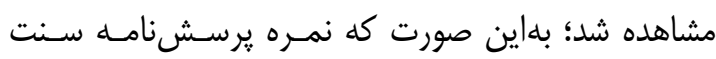

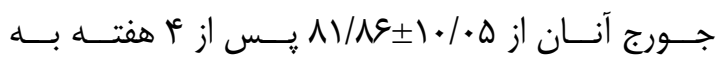

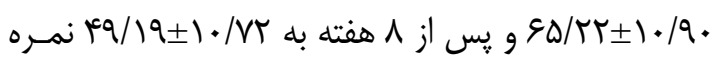

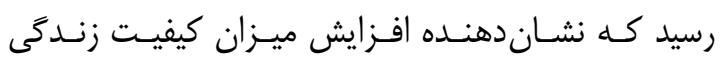
مىباشد. مسيد كله نشان

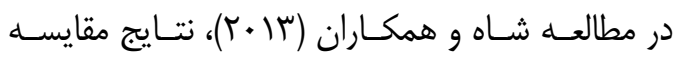

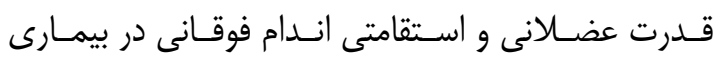




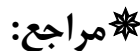

1. Mohammed J, Derom E, Van Ooster wJ, DaSilva $\mathrm{H}$, Calders P. Evidence for aerobic exercise training on the autonomic function in patients with chronic obstructive pulmonary disease (COPD): a systematic review. Physiotherapy 2018; 104(1): 36-45. doi: 10. 1016/j.physio.2017.07.004.

2. Lange P, Celli B, Agusti A, Boje Jensen G, Divo M, Faner R, et al. Lung-function trajectories leading to chronic obstructive pulmonary disease. N Engl J Med 2015; 373(2): 111-22. doi: 10.1056/NEJMoa 1411532.

3. Salvi SS, Bames PJ. Chronic obstructive pulmonary disease in non- smoker. Lancet 2009; 374(9691): 733-43. doi: 10.1016/ S0140-6736(09)61303-9.

4. Mathers CD, Loncer D. Projection of global mortality and burden of disease from 2002 to 2030. PLoS Med 2006; 3(11): e442. doi: 10.1371/journal.pmed.0030442.

5. Ivor B, Griggs RC, Wing EJ, Fitz GJ. Andreoli and Carpenter's cecil essentials of medicine. Azizian A. 8th ed. Tehran: Andisheh Rafie; 2011. 23-45. [In Persian]

6. Celli BR, Zuwallack RL. Pulmonary rehabilitation. In: Broaddus VC, Mason RJ, Ernst JD, King ET, Lazarus SC, Murray JF, Nadel JA. Murray \& Nadel's textbook of respiratory medicine. 6th ed. Elsevier 2016; 2: 1821-30. doi: 10.1016/B978-1-4557-33835-00105-6.

7. Nyberg A, Carvalho J, Bui KL, Saey D, Maltais F. Adaptations in limb muscle function following pulmonary rehabilitation in patients with COPD a review. Rev Port Pneumol 2016; 22(6): 342-50. doi: 10.1016/j. rppnen.2016.06.007.

8. Mirbagher-Ajorpaz N, Rezaei M. The
مقايسه با كروه تمرينهــاى تنفسـى كـه فقـط اقــام بــهـ

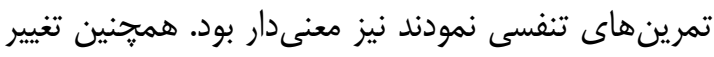

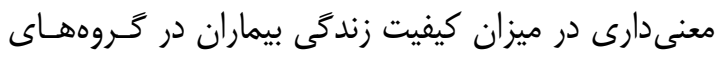

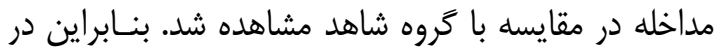
امر بازتوانى ريه، انجام ورزش اندامهاى فوقانى در مقايسه

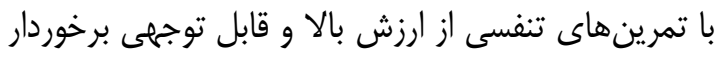

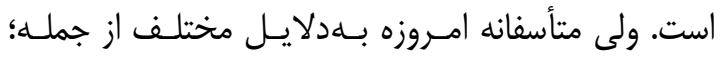

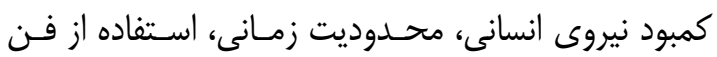

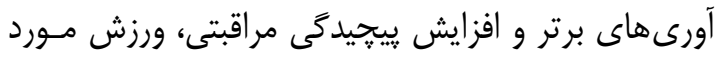

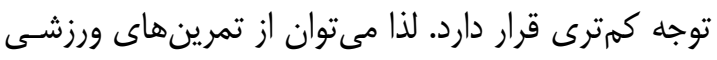

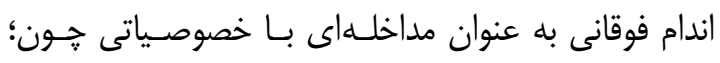

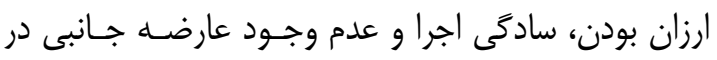
جهت بهبود توان و ظرفيت ورزشى بيماران بجره برد.

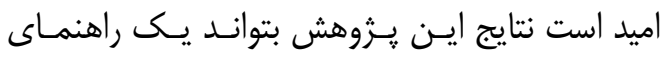

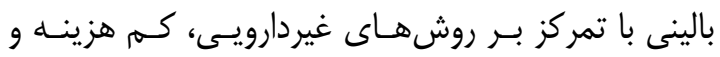

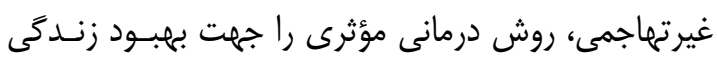
افراد مبتلا، معرفى نمايد. از محدوديتهـاى ايــن مطالعـهـ مى توان به موارد زير اشاره نمود:

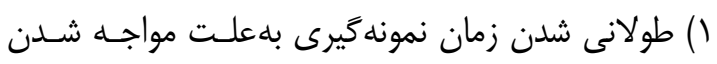

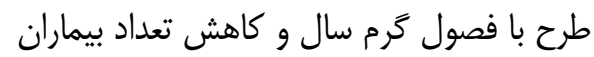
r) عدم شركت برخى از بيماران در طرح بهدليل طـولانى بودن برنامهها

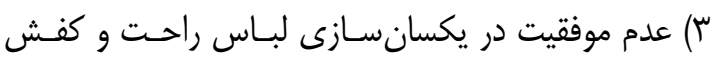

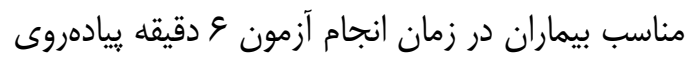
(ا) اجراى مطالعه در مدت زمان كوتاه (يكماهه)

\section{كاس}

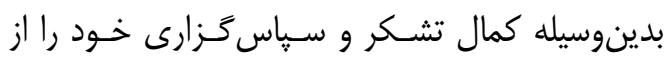

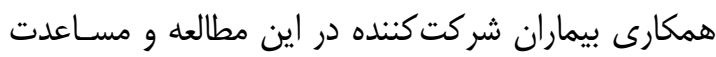

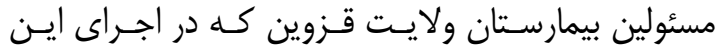
يثوهش ما را يارى نمودند، ابراز مى داريم. اين مطالعـه بـاــا

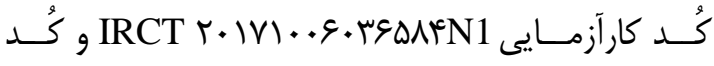
اخلاق IR.QUMS.REC.1395.293 در دانشخاه علسوم

$$
\text { يزشكى قزوين به ثبت رسيده است. }
$$


effect of pulmonary rehabilitation program on quality of life of elderly patients with chronic obstructive pulmonary disease. Zahedan J Res Med Sci 2011; 13(1): 30-5. [In Persian]

9. Jokar Z, Mohammadi F, Khankeh H R, FallahTafti S, Koushesh F. Comparing Home-based Pulmonary Rehabilitation Nursing on Fatigue and quality of life in Patients with COPD. J Fasa Univ Med Sci 2014; 4(2): 168-76. [In Persian]

10. Moy ML, Weston NA, Wilson EJ, Hess ML, Richardson CR. A pilot study of an internet walking program and pedometer in COPD. Respir Med 2012; 106(9): 1342-50. doi: 10.1016/j.rmed.2012.06.013.

11. Kathiresan G, Jeyaraman SK, Jaganathan J. Effect of upper extremity exercise in people with COPD. J Thorac Dis 2010; 2(4): 223-36. doi: 10.3978/j.issn.2072-1439.2010.11.4.

12. Rise AL, Ellis B, Hawkins RW. Upper exercise training in chronic obstructive pulmonary disease. Chest 1988; 93(4): 68892. doi: 10.1378/chest.93.4.688

13. Pan L, Guo YZ, Yan JH, Zhang WX, Sun J, Li BW. Does upper extremity exercise improve dyspnea in patients with COPD? A metaanalysis. Respir Med 2012; 106 (11): 1517-25. doi: 10.1016/j.rmed.2012.08.002.

14. Shah S, Nahar P, Vaidya S, Salvi S. Upper limb muscle strength \& endurance in chronic obstructive pulmonary disease. Indian J Med Res 2013; 138(4): 492-6.
15. Elkhateeb NB, Elhadidi AA, Masood HH, Mohammed AR. Pulmonary rehabilitation in chronic obstructive pulmonary disease. Egypt J Chest Dis Tuberc 2015; 64(2): 359-69. doi: 10.1016/j.ejcdt. 2015.03.001.

16. Nasser BA, AL-shenqiti AM, Ali AH, AlJeraisi TM, Gunjan GG, Awaidallah MF. Effect of a short term pulmonary rehabilitation programme on exercise capacity, pulmonary function and health related of life in patients with COPD. J Taibah Univ Med Sci 2017; 12(6): 471-6. doi: 10.1016/j.jtumed.2017. 07.005.

17. Ferrer M, Villasante C, Alonso J. Interpretation of quality of life scores from the St George respiratory questionnaire. Eur Respir J 2002; 19(3): 405-13.

18. Elmorsi AS, Eldesoky ME, Abdelwahab Mohsen MA, Shalaby NM, Abdalla DA. Effect of inspiratory training on exercise performance and quality of life in patients with chronic obstructive pulmonary disease. Egypt J Chest Dis Tuberc 2006; 65(1): 41-6. doi: 10.1016/j.ejcdt.2015.10.006.

19. Tout R, Tayara L. Halimi M. The effects of respiratory muscle training on improvement of the internal and external thoracopulmonary respiratory mechanism in COPD patients. Ann Phys Rehabil Med 2013; 56(3): 193-211. doi: 10.1016/j.rehab.2013.01. 008 . 